\title{
Fuzzy Fatigue Failure Model to Estimate the Reliability of Extend the Service Life of Rolling Stock
}

\author{
Dr. Waail Mahmod Lafta \\ Computer Engineering Technology Dept. Al-Yarmouk University College Baghdad - Iraq.
}

\begin{abstract}
In this paper we use fuzzy set of methods to solve one of the important problems in mechanical engineering: Reliability of Extending the Service Life of Rolling Stock by using Fuzzy Fatigue failure model. The residual service life for rolling stock can be changed depending on its use conditions. This paper presents a new method depending on fuzzy set theory by using the fatigue stress mathematical model to determine the residual service for rolling stock with the value of risk of its use in future. The proposed method used solid works and (Ansys) abilities with especial Fuzzy logic programs in MATLAB.
\end{abstract}

\section{Introduction}

The simple definition of reliability is the ability of an apparatus, machine, or system to consistently perform its intended or required function or mission upon demand and without degradation or failure. High equipment reliability is a choice rather than a fortune. To a great extent you can choose intervals between equipment failures. You can attain high equipment reliability by reducing the incidents that cause failures of equipment parts. The secret of remarkably long and trouble-free equipment life is to keep its parts and components at low stress in good local environmental conditions with a view to keeping it operational as per its design duty. If there is nothing to cause a failure, the failure will not happen and your equipment continues in service at full capacity and full availability [1].

The concept of service life means the period from the beginning of using the tool or machine to the time when it becomes unsafe or non-economic to use. This concept is of great importance for vehicles used to carry large numbers of people, such as: planes, trains and those special means which we are trying to reduce the probability of their failures to the minimum, such as military mobile equipment. The service life of any equipment depends on the intensity and quality of its use. Hence, the service life of the equipment changes significantly as per these factors. Since the term or concept (the density and quality of use) is not specific or Fuzzy, we can say that the service life function is Fuzzy (nonspecific) too. The service life of the equipment $\left(T_{R}\right)$, however, can be determined by the following equation number (1).

$$
\mathrm{T}_{\mathrm{R}}=\mathrm{T}_{\mathrm{D}}-\mathrm{T}_{\mathrm{S}}
$$

Where $T_{D}$ - means the service life of specified equipment as designed (by manufacturer) and TS means the service life of the equipment from the date of putting it into operation to the time of testing.

Factually, we are frequently forced to deal with the equipment without having detailed information about the record of its use when we are to maintain it. This leaves us with no clear picture of the system, its future operation and the remaining time it may continue operational. To determine the remaining service life of the equipment depends today on studying the equipment's condition without taking into account the Fuzzy factors (nonspecific) that affect its function. In this paper we present a new theory to determine the remaining service life of the equipment by studying the Fuzzy factors (nonspecific) that affect it, a theory which relies on the (Fuzzy Set theory).

The most important factors that affect the service life of the equipment are:

- Fatigue failure,

- Corrosion and Erosion,

- Cracks.

These factors play significant role when studying their effect on the service life of the rolling stock. This effect, however, changes according to several conditions: The intensive operation of the rolling stock, the environment and weather of operation. Figure No.1 gives an idea about the effect of these factors in countries of hot and dry weather [3]. 


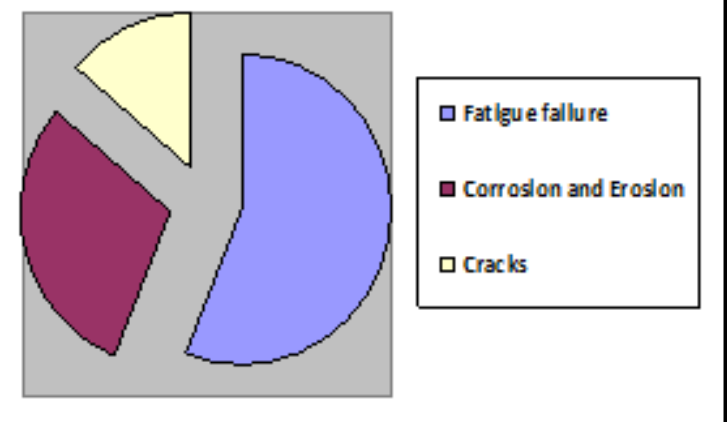

Fig.(1) the most important factors that affect the service life of the rolling stock

This diagram shows that the Fatigue failure plays a greater role in determining the remaining service life of the equipment.

\section{Fuzzy Logic}

The emergence of a Fuzzy theory is a revolution in the development of classical algebra and an upgrade of a higher level to the extent that it is now possible to take the unspecified information and data of the mathematical modeling process, that make it a problem to absorb information and more data in a mathematical model.

The Fuzzy theory is based on the idea of removing the boundaries of the group by the logic of classical groups algebra which says that every group contains a specified number of elements, and any element which does not belong to the group cannot be linked to it whatsoever, a matter that almost contradicts the human nature and behavior.

The mathematical stripping of everything around us was necessary to help us do the mathematical simulation of any phenomenon we need to address and control. It seems, however, that the scientific progress, the IT development and the so many new discoveries, have made it necessary to expand the mathematical abstraction with a view to simulating any natural phenomenon according to its nature away from abstraction so that we can address it easily and smoothly. Hence, the idea of Fuzzy groups plays a significant role in the expression of groups as a solution for the dilemma of the limited simulation of phenomena. Instead of answering with yes or no to the question whether a specified element belongs certain group or not, the question is now that if such an element belongs to a certain group, what is the degree of its affiliation to the group? The degree of affiliations is the spectrum between zero and one. This means that there is a factor describing these values, which is called the "Membership Factor".

Accordingly, the logic of "yes or no - true or false - white or black" can be considered now as a special case of progressive gray areas locating between the white and black areas. This is why it is called "Fuzzy" [4].

Fuzzy theory allows us to expand the mathematical simulation of the phenomenon. To depend on the mechanisms of a project, which we get in a specific and classic way, we will come out with only an idea about the number of these mechanisms. But when we try to know the set of mechanisms that the mechanical technicians can use, we will fall in the trouble of judging whether they belong to the group or not. It is well known that equipment readiness depends on many factors whose impact varies as per climatic and environmental conditions. Hence, the question is how we can reflect this group within the logic of Yes - No. This indicates that we must take into account the Fuzzy groups and its presentation [5]. The principal objective of the Fuzzy theory is not to remove the Fuzzy ambiguity but also to recognize its existence and its impact on the mathematical model.

There was confusion between the concepts of possibilities and Fuzzy groups because the distribution and membership factors are similar. This is why we must keep in mind the difference between them. While we try to predict the future by statistics, we can disclose the elements of the mathematical model which have no digital reflection and define them as a Fuzzy set through the search for more frequent values by simulating the Fuzzy groups.

We call the group Fuzzy (Fuzzy) A in X, a matter which is expressed as follows:

$$
A=\left\{\left(x, \mu_{A}(\text { (2) }) \mid x \in X\right\}\right.
$$

Where $\mu_{\mathrm{A}}(\mathrm{x})$ is the degree of which the element $\mathrm{x}$ belongs to the Fuzzy group A whose values are between $[0,1]$. 
It is mathematically common to find a membership factor for any group from within if the form and nature of the membership factor has a great impact on defining it. Here, we must take into consideration the effect of the subjective element. To alleviate this impact, we must take into account the other factors affecting the formation of membership factor.

Generally, we can divide the factors into linear and nonlinear. In the case of non-linear, the concave or curvature plays a role in the optimistic or pessimistic evaluation we do through the mathematical model [6].

\section{Residual Service Life as Fuzzy Factor (Fatigue Model)}

Usually the remaining service life of a rolling stock is determined on the basis of the Fatigue strength as shown in formula $[7,8]$ :

$$
T_{K}=\frac{\left(\frac{\sigma_{a, N}}{[n]}\right)^{m} \cdot N_{o}}{\sigma_{a, e}}
$$

Where:

$T_{K} \rightarrow$ The residua service life of rolling stock;

$[n] \rightarrow$ The safety factor;

$m \rightarrow \quad$ The degree of the Fatigue failure curve;

$N_{o} \rightarrow \quad$ The number of cycles $10^{7}$;

$\sigma_{a, N} \rightarrow$ The Dynamic stress acting to the machine, MPa;

$\sigma_{a, e} \rightarrow$ The average value of the endurance limits of diagnoses material, MPa.

Equation no.(3) shows that there are factors which may be used as Fuzzy factors (nonspecific) as follows:

1. The safety factor (n): The value of the safety factor can change depending on several conditions. As such, we can consider it as a Fuzzy factor.

2. The degree of the Fatigue failure curve $(\mathrm{m})$ to the selected or tested parts of a rolling equipment: This value of this factor depends on the material of which those parts are made and the Thermal Treatment of them. If this information is missed, this factor can be considered a Fuzzy factor according to a triangular membership function $\langle 4.0 ; 4.0 ; 6.0\rangle$.

3. The endurance average value of the material of which rolling equipment is made (MPa): The endurance limit of the material of which rolling equipment is made, can be taken as Fuzzy factor according to a normal distribution. In this case, its membership function is the inverse of the exponential.

Now we can rewrite eq. (3) as Fuzzy remaining Service Life Function:

$$
\widetilde{T}_{K}=\frac{\left(\frac{\sigma_{a, N}}{[\tilde{n}]}\right)^{\tilde{m}} \cdot N_{o}}{\tilde{\sigma}_{a, e}},
$$

Where the above symbol $\tilde{T}_{k}$ means that the factor is Fuzzy. Table (1) represents the membership functions for the above Fuzzy factors.

\section{Suggestion Theory \& Its Application}

The suggestion theory consists of three steps as shown in Fig (2). The first step is to collect all the initial information about the rolling equipment to be studied. This must include all the information about the machine design, operation and the conditions surrounding it. The second step is to formulate the membership function for the Fuzzy factors and the finite element module to determine the high and low stress regions. Thus, we must build the mathematical model with the Fuzzy factors from step 1. At the third step, by using the abilities of ANSYS, Solid Works and MATLAB, we can estimate the membership function of the remaining service life of the rolling equipment and how reliable it is.

For the application of this theory, we have selected equipment called "Hopper Ballast Wagon for transport and lying ballast", from several types of mobile equipment, because it is used to fresh gravel when 
making or maintaining new or old railway lines, and works extreme weather conditions, such as high humidity and temperature, rain and other heavy load conditions on the one hand. On the other hand the role of this equipment is to distribute gravel on all parts of the railway or road, a matter that puts high stress and pressure on some parts of the equipment leading to a reduction in their efficiency and subjecting them to recurrent failures. To apply the theory, we have selected the most important part of the equipment which is gravel loading and unloading (Hopper). Figure (3) shows the general appearance of the equipment.

Step 1: From the last analysis of the remaining service life according to Fatigue stress criteria, we can specify the active Fuzzy factors by which we can determine the remaining service life of rolling equipment. Table (1) shows the membership function of these Fuzzy factors [7, 8].

Table (1) The Membership function of Fuzzy Factors

\begin{tabular}{|c|c|c|c|}
\hline No. & Fuzzy Factors & \multicolumn{2}{|c|}{ Membership Function * } \\
\hline 1 & The Safety Factor (n) & $\mu_{n}=\left\{\begin{array}{c}1-\frac{1.5-x}{0.5} \\
1-\frac{x-1.5}{0.5} \\
0\end{array}\right.$ & $\begin{array}{c}1.0 \leq x \leq 1.5 \\
1.5 \leq x \leq 2 \\
\text { other }\end{array}$ \\
\hline 2 & $\begin{array}{l}\text { The degree of the Fatigue } \\
\text { Failure Curve }(\mathrm{m})\end{array}$ & $\mu_{m}=\left\{\begin{array}{c}1 \\
1-\frac{x-4.0}{0.2} \\
0\end{array}\right.$ & $\begin{array}{c}x=4.0 \\
4.0 \leq x \leq 4.2 \\
\text { other }\end{array}$ \\
\hline 3 & $\begin{array}{l}\text { The average value of the } \\
\text { material Endurance Limit of } \\
\text { rolling stock }\end{array}$ & $\mu_{\sigma}=e$ & $\left(\frac{\sigma-360}{23}\right)^{2}$ \\
\hline
\end{tabular}

* According to the experimentally information in the references [7, 8].

\begin{tabular}{|c|c|c|c|}
\hline \multicolumn{4}{|c|}{ 1. Collect initial information: } \\
\hline & Type of information & Collection method & What will get \\
\hline 1 & $\begin{array}{l}\text { The original design } \\
\text { parameters. }\end{array}$ & $\begin{array}{l}\text { - Design documentation, } \\
\text { - Really measurements, } \\
\text { - Analysis of results } \\
\text { thickness. }\end{array}$ & $\begin{array}{l}\text { - The size of elements, } \\
\text { - The thickness of the elements, } \\
\text { - Thickness tolerance. }\end{array}$ \\
\hline 2 & $\begin{array}{l}\text { Parameters of operation of } \\
\text { the rolling stock. }\end{array}$ & $\begin{array}{l}\text { - Passport of machines, } \\
\text { - operational documentation. }\end{array}$ & $\begin{array}{l}\text { - Mean time (Hours or kilometers. Of using) in the } \\
\text { working and transport modes. }\end{array}$ \\
\hline 3 & $\begin{array}{l}\text { Parameters of loading the rolling } \\
\text { stock } \\
\text { - in transport mode, } \\
\text { - in working mode. }\end{array}$ & $\begin{array}{l}\text { - Equations, } \\
\text { - Really measurements, } \\
\text { - Mathematical models. }\end{array}$ & $\begin{array}{l}\text { - Rated load, } \\
\text { - Experimental load. }\end{array}$ \\
\hline 4 & $\begin{array}{l}\text { Properties of the material of } \\
\text { construction of the rolling stock. }\end{array}$ & $\begin{array}{l}\text { - Legal documentation, } \\
\text { - Non-destructive testing, } \\
\text { - Destructive testing, } \\
\text { - Mathematical modeling. }\end{array}$ & $\begin{array}{l}\text { - Experimental material properties, } \\
\text { - Calculated properties of the material, } \\
\text { - The residual service life in standard }\end{array}$ \\
\hline 5 & Results of technical diagnosis. & $\begin{array}{l}\text { - Measurement of the } \\
\text { elements, } \\
\text { - Non-destructive testing. }\end{array}$ & $\begin{array}{l}\text { - The actual size of the elements and it is } \\
\text { geometrically deviation from the standard. } \\
\text { - The actual thickness according to the } \\
\text { mechanical and chemical corrosion, } \\
\text { - Estimating the size of internal defects. }\end{array}$ \\
\hline 6 & Unknown factors & - Overall testing of the machine. & $\begin{array}{l}\text { - Distribution of vertical load, } \\
\text { - Acceleration of the body }\end{array}$ \\
\hline
\end{tabular}




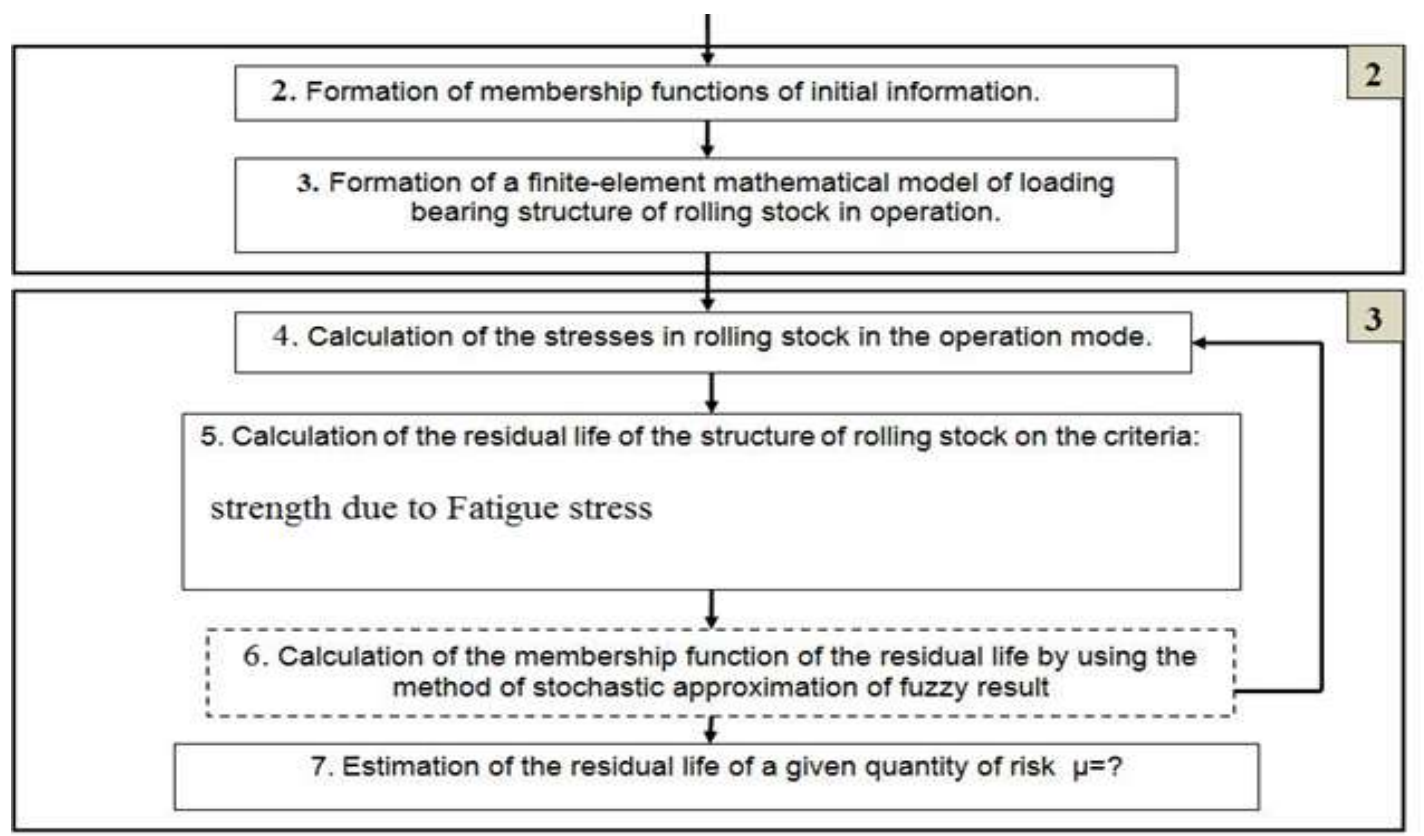

Fig. (2) Shows the flow chart for estimating the remaining service life of the rolling equipment structures.

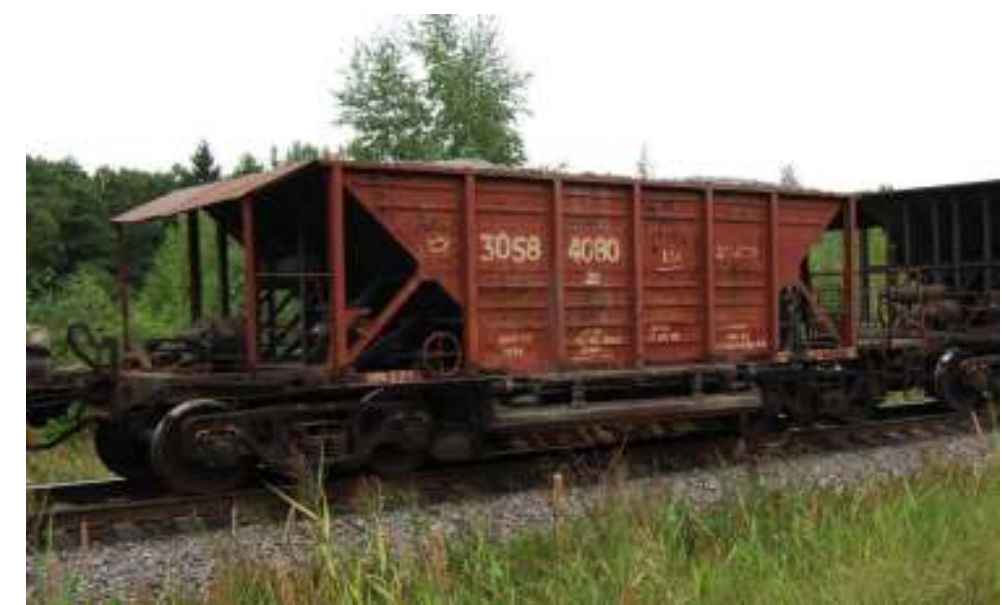

Figure (3) represents the overall appearance of the equipment.

Step 2: By using the facilities of computer engineering software like (Solid Works) and (ANSYS) we built a model as shown in Figure (4), where we have entered all the factors affecting the machine during transportation and working conditions.

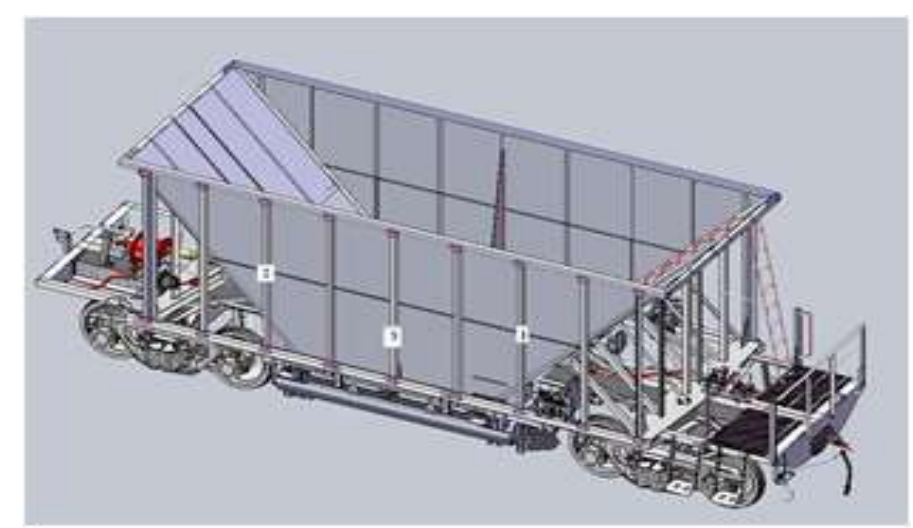

(a)

Fig. (2). Flow chart for estimate the reliability of extended the service life of rolling stock 


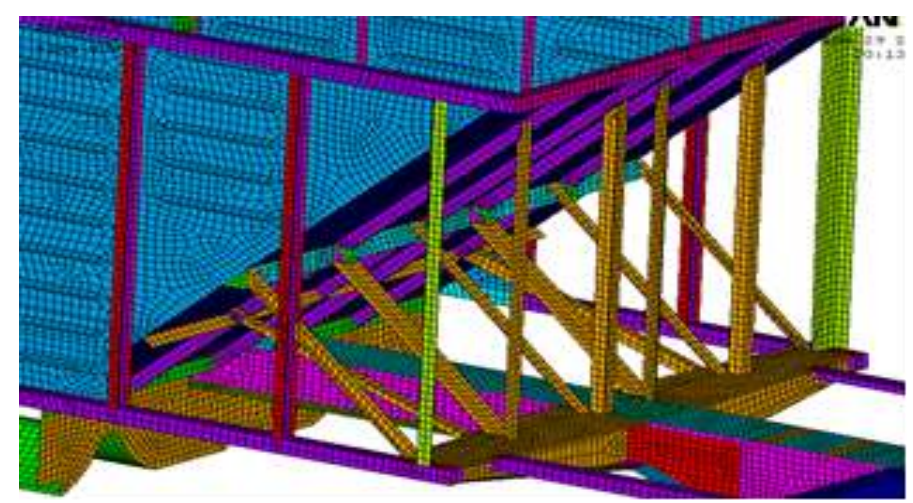

(b)

Fig.(4). (a) The model under study (Solid works model) (b) The model is divided by Finite Elements Method (by using ANSYS)

At this stage, we also detect the input belonging function through the identification of Fuzzy factors that affect the service life of the machine and its relationship with the input data. The mathematical model of eq. (4) was approved.

Step 3: depending on the (ANSYS) program, we have calculated the stress value on the equipment's hopper with a view to finding the high and low stress areas regions on the hopper and calculating the stress on the metal in several points of it. Depending on the model above and the MATLAB program, we can get the actual stress affecting the hopper and compare it with the maximum allowable stress on the metal, and by repeating this process we can determine the remaining service life of the equipment.

\section{Results}

For the studied case, the service life of the equipment is 20 years, but by the application of this theory (where the maximum allowable stress of the metal is $190 \mathrm{MN} \backslash \mathrm{m}^{2}$ ), we found out that the equipment could work for an additional 5 years with a reliability of $96 \%$ (the using risk is $4 \%$, where Risk=1- Reliability) and 9 years with a reliability of $90 \%$ (risk $10 \%$ ) as in fig. (5).

By using this method we can find the remaining service life of the machine as well as the rate risk when using it. From the curve below, it is very clear that the machine can work for 3 years with a reliability of $100 \%$.

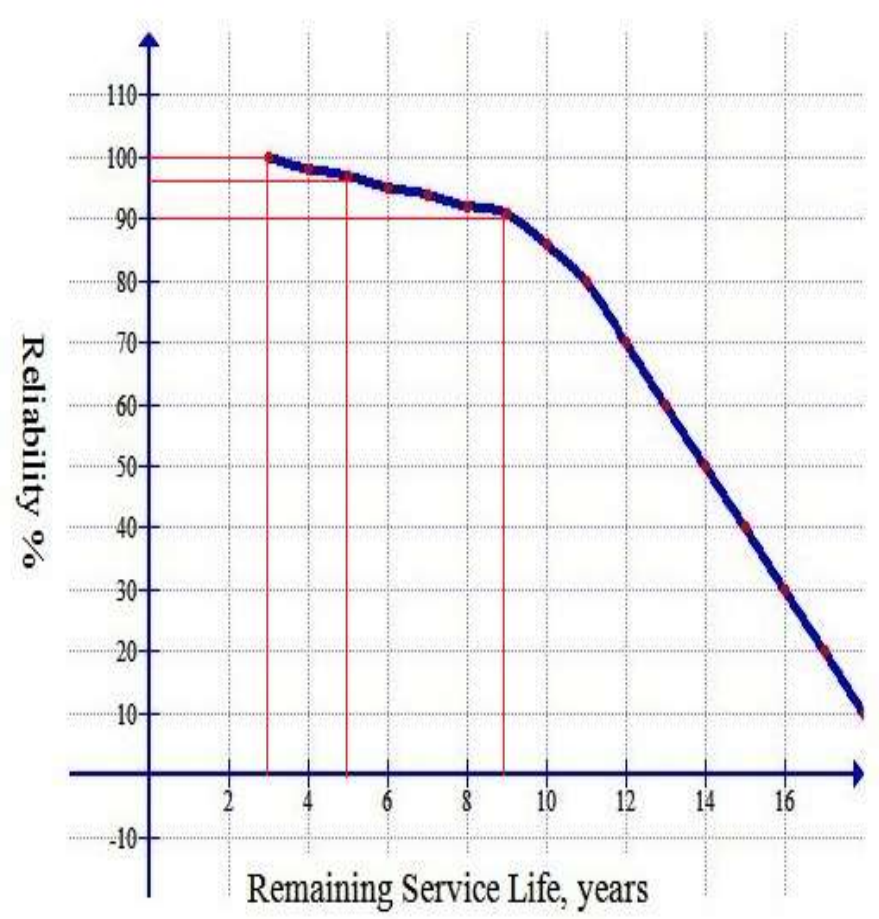

Fig. (5). The remaining service life of the studied machine 


\section{Discussion \& Conclusion}

As we have already indicated, by using the above cure we can find the reliability of remaining service life of a machine by using the aforementioned method. Moreover, we can determine the risk rate depending on the intensive operation of the machine. This step leads us to find the remaining service life of a machine.

In this paper, we have studied the effect of one factor (fatigue failure) to calculate the reliable remaining service life of a machine and neglected the effect of other factors (mechanical and chemical corrosion and cracks). For future studies, we recommend to develop new method to calculate the remaining service life of a machine by studying the effect of all these factors (mechanical and chemical corrosion, fatigue failure and cracks) depending on the Fuzzy set theory.

\section{References}

[1] Bandemer H., Gebhardt A. BAYESian fuzzy kriging// Fuzzy Sets and Systems, 2000. - №112. - pp. $405-418$.

[2] Bellinger N.C., Komorowsky J.P., Benak T.J. Residual life predictions of corroded fuselage lap joints// Int. J. of Fatigue, 2001. №23. - pp. S349-S356.

[3] Waail M. Lafta, Analysis the Strength of Rolling Stock working in Uncertainly Conditions, LAP LAMBERT Academic Publishing GmbH \& Co. KG,Germany 2011, ISBN: 978-3-8465-9806-1.

[4] Buckley J. J., Feuring T. Universal approximators for fuzzy functions// Fussy sets and systems, 2000. - №113. - pp. 411-415.

[5] Donders S., Vandepitte D., Van de Peer J., Desmet W., The short transformation method to predict the FRF of dynamic structures subject to uncertainty// Proc. of ISMA 2004, International Conference on Noise and Vibration Engineering, Leuven, Belgium, 2004, pp. 3043-3054.

[6] Hanss M., Willner K.. A fuzzy arithmetical approach to the solution of finite element problem with uncertain parameters// Mechanics Research Communication, 2000. - Vol. 27. - No. 3. - pp. 257-272.

[7] Sokolov A. M., Methods and algorithms of Fuzzy simulation of mechanical systems//Saint Petersburg,2006. ISBN 5-901739-35-3.

[8] Waail M. Lafta, Estimate the Residual Service Life of Rolling Stock with incompletely information, LAP LAMBERT Academic Publishing GmbH \& Co. KG, Germany 2011, ISBN: 978-3-8465-2512-8. 